\title{
Categorizing short term readmissions in an academic emergency department in North India: exploring approaches to reduce them
}

\author{
Dolly Chandrabhan Yadav ${ }^{*}$, Prasad Chidanandan Siddalingeswara, Tamorish Kole \\ From EMCON 2014: International Conference on Emergency Medicine; 16th Annual Conference by the \\ Society for Emergency Medicine in India (SEMI) \\ Mumbai, India. 6-9 November 2014
}

\section{Objective}

Categorizing short term readmissions in Emergency Department (ED) and exploring methods to reduce avoidable ED readmissions.

\section{Introduction}

Readmissions in the ED are multifaceted. A recent metaanalysis showed that less than a quarter of readmissions could be considered avoidable [1]. Less is known regarding the systemic causes of readmissions [1]. Research till now, has focused on the risk factors predictive of readmissions and identifying the most common diagnosis [2-4]. A study was undertaken to identify factors associated with this quality care indicator.

\section{Method}

Prospective observational data from electronic hospital and patient health records were collected from $1^{\text {st }}$ September 2013 through $31^{\text {st }}$ August 2014 at Max Superspecialty Hospital, Saket, New Delhi, India. Number of readmissions within 72 hours of index ED registrations were considered. Exclusive and hierarchical categorizations of readmissions within 72 hours of index ED registrations were done under the following categories: (1) Avoidable readmissions- (1a) Readmissions due to inadequate care, (1b) Readmissions due to poorly managed transitions during discharge; (2) Unavoidable readmissions- (2a) Readmissions due to complications, (2b) Readmissions due to recurrences; (3) Unrelated readmissions (different body systems); (4) Other planned readmissions; (5) Readmissions after LAMA (Leaving Against Medical Advice). Statistical analysis was done

* Correspondence: dollyyadav03@gmail.com using SPSS 16.0 and cross-tabulation technique was applied on patient variables.

\section{Results}

A total of 19,205 ED registrations took place from $1^{\text {st }}$ September 2013 through $31^{\text {st }}$ August 2014. Of these 473 patients $(2.46 \%)$ were readmitted within 72 hours of their index ED registrations. Rate of short term ED readmission and ED registrations showed minimal monthly variability. The mean age of patients was 43 years. Amongst the short term ED readmissions, males (253) outnumbered females (220) marginally. Of 473 short term readmissions, 181 (38\%) were avoidable readmissions followed by $86(18 \%)$ unrelated readmissions followed by 82 (18\%) unavoidable readmissions followed by $76(16 \%)$ who were readmitted after signing LAMA followed by $48(10 \%)$ planned readmissions. In the avoidable short term ED readmission category, 66 (36\%) readmissions were due to inadequate care while 115 (64\%) were poorly managed transitions during discharge from the ED. In the unavoidable short term ED readmission category, 44 (52\%) patients got readmitted due to complications while 38 (48\%) were due to recurrences of signs and symptoms.

\section{Discussion}

A readmission could be due to healthcare factors- hospital or primary care, or patient factors- disease and management plan understanding, compliance and adequate follow up. Our analysis suggests that improving the transition during discharges by bridging the gap and sustaining the quality of care between hospital and home can improve patient outcome.

For this, interventions need to be targeted at three levels [5]: (1) Pre-discharge interventions- discharge planning

\section{SpringerOpen ${ }^{\circ}$}

(C) 2015 Yadav et al; licensee Springer. This is an Open Access article distributed under the terms of the Creative Commons Attribution License (http://creativecommons.org/licenses/by/4.0), which permits unrestricted use, distribution, and reproduction in any medium, provided the original work is properly cited. 
including patient education (2) Post-discharge interventions- home care and ambulance services, appointing case managers or transition care managers (3) Administrative interventions- ED readmission policy, readmission prevention checklist and automated indicators in electronic hospital and patient health records.

\section{Conclusion}

There needs to be further studies and analysis identifying causes of readmissions and ways to reduce them.

Published: 22 April 2015

\section{References}

1. Van Walraven C, Jennings A, Forster A: A meta-analysis of hospital 30-day avoidable readmission rates. J Eval Clin Pract 2012, 18: 1211-8.

2. Billings J, Dixon J, Mijanovich $\mathrm{T}$, et al: Case finding for patients at risk of readmission to hospital: development of algorithm to identify high risk patients. BMJ 2006, 333:327-30.

3. Halfon P, Eggli Y, Prêtre-Rohrbach I, et al: Validation of the potentially avoidable hospital readmission rate as a routine indicator of the quality of hospital care. Med Care 2006, 44:972-81.

4. Donze J, Lipsitz S, Bates B, et al: Causes and patters on readmissions in patients with common comorbidities: retrospective cohort study. BMJ 2013, 347:f7171.

5. Hunter T, Nelson JR, Birmingham : Preventing readmissions through comprehensive discharge planning. Prof Case Manag 2013, 18(2):56-63.

doi:10.1186/1865-1380-8-S1-O2

Cite this article as: Yadav et al:: Categorizing short term readmissions in an academic emergency department in North India: exploring approaches to reduce them. International Journal of Emergency Medicine 2015 8(Suppl 1):O2.

\section{Submit your manuscript to a SpringerOpen ${ }^{\odot}$ journal and benefit from:}

- Convenient online submission

- Rigorous peer review

- Immediate publication on acceptance

- Open access: articles freely available online

- High visibility within the field

- Retaining the copyright to your article 